Revista Internacional de Sociología (RIS)

Vol.68, No 1, ENERo-ABRIL, 9-18, 2010

ISSN: 0034-9712

elSSN: 1988-429X

DOI:10.3989/ris.2008.01.13

\title{
EL TEOREMA DE POSIBILIDAD
}

\section{THE POSSIBILITY THEOREM}

\author{
SALVADOR GINER \\ Institut d'Estudis Catalans. Barcelona. España \\ sginer@diginter.com
}

\section{RESUMEN}

La explicación sociológica del altruismo presenta serias dificultades. El presente ensayo propone resolver el enigma del altruismo mediante la presentación de una explicación alternativa al Teorema de Imposibilidad de Arrow así como a las objeciones de Berlin al cálculo racional en política. La atribución de carisma o sacralidad a ciertos valores genera, frecuentemente, la solución. Tal atribución suministra un criterio racional de acción que supera y descarta otros cálculos. El Teorema de Posibilidad que aquí se postula resuelve el problema de la racionalidad de lo supuestamente irrracional en las trías o elecciones racionales de conducta. El Teorema propuesto es una aportación a la cuestión de la racionalidad del carisma y, por ende, a la explicación analítica del altruismo.

\section{Palabras Clave}

Altruismo, Carisma, Egoísmo, Racionalidad.

\section{ABstract}

The sociological explanation of altruistic behaviour often encounters serious difficulties. This essay attempts to solve the altruism enigma through the presentation of an alternative explanation to Arrow's Possibility Theorem as well as to Berlin's serious objections to rational calculus in political behaviour. Bestowing charisma and/or sacredness to certain values often proves the solution to the puzzle by providing a rational criterion for action which cancels out other criteria and calculations. The Possibility Theorem which is put forward here solves the problem of the rationality of the supposedly irrational in rational choice situations and dilemmas. The Possibility Theorem is a contribution to the issue of the rationality of charisma and, therefore, to the analytical explanation of altruistic behaviour.

\section{KEYWORDS}

Altruism, Charisma, Rationality, Selfishness. 
La explicación científica de la conducta social humana avanzó considerablemente merced a hipótesis sociológicas basadas en una teoría causal que incluyera las intenciones, la racionalidad y los recursos disponibles para los agentes. ${ }^{1}$ (Los recursos incluyen, a su vez, creencias y conocimiento, así como la situación del individuo en la estructura social). El individualismo metodológico, en combinación con la lógica situacional, ha sido la perspectiva más convincente para el logro de una explicación científico-social de la conducta humana, si bien ese enfoque no agota todas nuestras herramientas epistemológicas en este campo².

Sin embargo, la explicación del altruismo, la caridad, la fraternidad y la solidaridad desde el punto de vista del individualismo metodológico no ha sido siempre satisfactoria. La noción de un "egoísmo ilustrado" o inteligente, aunque ayuda frecuentemente a explicar el altruismo humano, no basta. Así, es claramente insuficiente en casos de comportamiento sacrificado, de coordinación cooperativa generosa y desprendida, y en muchos de magnanimidad, liberalidad y de otras orientaciones parejas. Por extensión, tampoco explica su contrario, conductas de entusiasmo o entrega a una causa que resulten en daños intencionados y víctimas inocentes. En este ensayo, empero, prestaré mucha mayor atención a la solución del enigma altruista.

Abunda la invocación de nociones culturalistas para explicar el altruismo. Apelar a las creencias en una ideología determinada —como son el liberalismo, el comunismo, el nacionalismo - o en una religión, para explicarlo posee un indudable atractivo estético. Como argumento es, no obstante, demasiado nebuloso. No garantiza una explicación causal del comportamiento altruista. Sobre todo habida cuenta de que el último se refiere, por definición, a terceros. La conducta altruista orientada hacia los míos, o los nuestros, -familia, clan, partido, tribu, facción, feligresía, secta, nación - no es de lo que aquí se trata. Es muy dudoso que cualquier expresión de "solidaridad interna" 0 "fraternidad grupal" sea genuinamente altruista, o solo altruista. Además, será difícil demostrar que musulmanes, cristianos, comunistas, liberales o cualquiera otra comunidad credencial se hayan conducido más generosa, altruistica y amablemente hacia una raza humana que contiene rivales, enemigos, extraños, forasteros, amén de quienes no comparten sus ideologías, por muy "caritativas", "compasivas" y "misericordiosas" que pretendieran ser. El altruismo es por definición una forma de conducta solidaria, dirigida a los otros, que va más allá de la tolerancia o la condescendencia.

\footnotetext{
${ }^{1}$ El presente ensayo es la traducción revisada de la ponencia The Possibility Theorem: Charismatic Sources of Solidarity and Altruism, presentada en el Congreso Internacional "Vecchie e Nuove Solidarietà", Roma, Junio, 2007. Una versión inglesa algo distinta aparece en M. Cherkaoui y P. Hamilton, eds. Raymond Boudon: A Life in Sociology Oxford: The Bardwell Press, 2009, Vol. III.

${ }^{2}$ Para una argumentación de las ventajas de la lógica situacional como aliada al individualismo metodológico, cf. Giner (1997).
} 


\section{II}

Los seres humanos no suelen conducirse altruistamente. Pero lo hacen con suficiente frecuencia como para que sea necesaria una explicación sociológica de ello. Las concepciones de Adam Smith sobre nuestra natural benevolencia en el seno de su teoría de los sentimientos morales no excluía - sino al contrario- las tendencias más egoístas de los hombres. Dependían más, no obstante, de una teoría de la naturaleza humana que de una teoría de la sociedad.

La tradición que inauguró Smith en la ciencia social para explicar el comportamiento altruista - benevolente en el lenguaje de la época, o filantrópico— era de por sí interesante, aunque pobre. Andando el tiempo Auguste Comte acuñaría la palabra "altruismo" como expresión sociológica técnica. Estaba destinada a entrar en el lenguaje corriente de nuestro tiempo ${ }^{3}$. (Donde a menudo sustituye la noción cristiana de caridad o la laica, y otrora libertaria, de solidaridad.) Comte tampoco suministró una explicación causal del fenómeno. Sus llamadas a una futura réligion de l'humanité ignoraban las condiciones sociales que posibilitan el altruismo o lo estimulan. Más tarde, diversas teorías económicas, políticas y sociológicas fundamentaron sus argumentos sobre interpretaciones de la conducta y estructura sociales apoyadas sobre la "hipótesis egoísta". (Tanto si se trata de egoísmo "ilustrado" o inteligente como si no.) Para ellas, la coordinación de muchas voluntades era el resultado de ciertas agregaciones y combinaciones de intereses egoístas. (Aunque la determinación de lo que tales intereses puedan ser continúa siendo, con frecuencia, enigmática.) Por su parte, la estructura social era entendida también como resultado de una pluralidad de voluntades, frecuentemente como coaliciones fruto de distribuciones de poder, privilegio u otras formas de desigualdad. La noción weberiana de "coordinación imperativa" —obediencia forzosa a un gobernante o jefe - y su análisis de las diversas suertes de dominio y autoridad ayudaron a compatibilizar una visión del hombre como ser siempre interesado en lo suyo con las duras realidades del poder en la vida social. Así, puede inducirse a gentes e instituciones a ser "generosos" y a asistir a los demás, a los otros, en sus necesidades. La legitimación de los impuestos y contribuciones en los tiempos democráticos modernos es una ilustración de ello. El altruismo así inducido no es altruismo.

En consecuencia, seguíamos sin una explicación satisfactoria del altruismo. Las interpretaciones neodarwinistas incluyen a veces la invocación a algunas inclinaciones generosas y desprendidas, que van más allá de la especie o grupo, pero no han resuelto todos los enigmas. Además, la sociobiología no es sociología. Ni la sociología permite que la reduzcamos a la biología.

Si somos siempre egoístas, en el sentido de que deseamos permanentemente, y por encima de todo, maximizar nuestros propios recursos, estatus y poder así como

\footnotetext{
${ }^{3}$ En su Cours de philosophie positive (1830-1842), procedente del italiano altrui, a su vez del latín alteri hui. En inglés aparece en los Principles of Psychology de Herbert Spencer.
} 
minimizar pérdidas o sufrimiento, ¿cómo podrá explicarse el altruismo de un modo que no lo subsuma bajo la noción de que es sólo un ejercicio en la búsqueda constante de estatus o poder? $\mathrm{O}$ bien, ¿cómo hacerlo sólo bajo la noción de que nos comportamos caritativa o fraternalmente únicamente para ganar acceso a los cielos, o aumentar la admiración 0 adulación que recibimos de nuestros congéneres, o por otro motivo ulterior? O, finalmente, ¿pagamos impuestos sólo para cumplir nuestra obligación moral de buenos ciudadanos, o lo hacemos porque se nos fuerza a contribuir al erario público? ¿No suele darse también el primer caso? La hipótesis excluyente de la maximización egoísta no admite la del altruismo genuino.

\section{III}

Por si no bastaran estos interrogantes, hay también un importante corolario a la "cuestión del altruismo". Asumamos que en algunos casos nos conducimos impelidos por solidaridad hacia nuestros congéneres no pertenecientes a nuestro clan, familia o comunidad, sean conciudadanos o simplemente miembros de la raza humana, ¿hay criterios racionales que nos permitan establecer un orden de prioridades en nuestra solicitud, dado que estamos en situación de recursos escasos? ¿Existe una buena razón sociológica que induzca a que nos conduzcamos altruistamente, más allá de las consabidas razones "indirectamente egoístas"? (Como son la búsqueda de prestigio, las recompensas celestiales, la reputación de la buena conducta, la de aparecer como buen miembro del partido, etcétera.) Cuando lo hacemos, ¿cuáles son las prioridades en la expresión de nuestra generosidad, desprendimiento o solicitud?

Según la teoría, no hay criterios claros. La paradoja de Arrow, o teorema de imposibilidad, demuestra que ninguna elección basada sobre un rango de preferencias satisface un conjunto de criterios cuando son varias las opciones (en condiciones mínimas de democracia) (Arrow, 1951). La significación de la paradoja de Arrow -y sin duda también el principio de eficiencia paretiano, afín al teorema arroviano- para el bienestar social se hizo evidente de inmediato. Puesto que las políticas sociales de bienestar son expresión de conducta altruista al nivel público, se comprende que los especialistas las consideren tan a menudo como explicaciones a nivel macrosocial de la solidaridad y la fraternidad.

La paradoja de Arrow y, antes de su formulación, el análisis de Pareto de las causas de las decisiones "fraternas", hacen hincapié en que debe existir por fuerza un elemento de arbitrariedad en la asignación de bienes y recursos en la dirección del bienestar, la igualdad y lo que muchos llaman, simplemente, justicia social. Arbitrariedad no es lo mismo que irracionalidad. (Las decisiones irracionales son arbitrarias, pero no todas las decisiones arbitrarias son irracionales.) El mundo está con frecuencia repleto de ambigüedades, mientras que ninguna ciencia positivista es capaz de establecer independientemente los criterios objetivos que regulen todas las decisiones. Las aporías y los dilemas son tan endémicos en la vida social como en la vida moral de cada uno 
de nosotros. Reconocer su existencia no significa abrazar el irracionalismo. Ni la ciencia natural ni el más refinado cálculo consecuencialista suministrará las respuestas. La incertidumbre acecha siempre en la mejor ciencia social.

Al reflexionar sobre la virtud del buen juicio en política, Isaiah Berlin demostró que el buen ejercicio del poder y la autoridad es, radicalmente, un arte. El arte de la política. El de gobernar. Berlin fundamentó su argumento precisamente sobre la idea de que las decisiones no pueden apoyarse ni en criterios científicos ni en grandes acopios de datos empíricos. Ningún cálculo felícifico benthamita podrá aplicarse nunca las políticas que fomenten la justicia, la redistribución equitativa y la mejora del bienestar social. La fuerza de la idea de Berlin surge de su abierto rechazo a cualquier concepción obscurantista del poder. "No hay virtud en la tiniebla", dice. Así, toda la posible evidencia empírica y todo análisis científico debe sacarse a relucir para ayudar a las autoridades responsables a actuar con prudencia y justicia. No obstante, toda política -incluso la política solidaria y fraterna- es siempre un arte (Berlin, 1996). La utopía tecnocrática podrá haber penetrado en la mentalidad de los gobernantes modernos pero, en última instancia, muchas de sus decisiones escapan a un orden prioritario presuntamente establecido por expertos.

\section{IV}

Tanto la paradoja de Arrow como el arte de gobernar de Berlin hacen hincapié en que las buenas decisiones públicas se fundamenten en la intuición, la buena voluntad, la opinión informada, la experiencia y, en especial, la sabiduría. Sus análisis respectivos son complementarios. Son razonables y merecen toda la atención que han recibido. Más allá de sus constataciones, no obstante, está el hecho de que muchas decisiones se toman según potentes afirmaciones sobre la naturaleza de la realidad que fuerzan a los agentes a actuar en una sola dirección, ajenos al oportunismo. Tales afirmaciones tajantes no encajan con los casos pragmáticos, calculadores, seculares e intuitivos a la vez a los que se refieren tanto Kenneth Arrow como Isaiah Berlin.

Para esclarecer el asunto, centraré mi atención sobre un elemento que impone una única línea de acción a los decisores, al tiempo que excluye otras. Me fijaré en la fuerza del carisma para engendrar acción y, en especial, actividad solidaria 0 altruista ${ }^{4}$. Sin duda pueden identificarse otras fuerzas que conforman asimismo el altruismo pero, por mor de y claridad, circunscribiré mis observaciones a los resultados que posee el carisma sobre el altruismo.

Según lo definió Weber el carisma no es un concepto cultural vago, capaz de instigar en los miembros de una comunidad — secta, iglesia, colectivo ideológico- un comportamiento en una dirección general. Es un atributo concreto. Confiere poderes sobrenaturales o excepcionales a ciertas personas u objetos. Es una propiedad extraordinaria

\footnotetext{
${ }^{4}$ Para un análisis detallado del carisma después de la aportación de Weber, Giner (2003).
} 
que se atribuye a ciertas individuos o cosas, símbolos, acciones y seres, reales o imaginarios. Como tal el carisma ni es "bueno" ni es "malo". Puede generar repercusiones beneficiosas para sus creyentes y nocivas para sus rivales, competidores, o víctimas. 0 al revés. También es posible que haya terceros que no queden afectados por su presencia.

El guía, las acciones, los símbolos y los objetos carismáticos —un texto sagrado, ya sea el Alcorán o el Libro Rojo de Mao, en su día- proyecta su aura sobre secuaces, seguidores y adoradores. Éstos afectan a los extraños que deben sufrir, soportar o beneficiarse de su actividad. Rara vez los efectos del carisma quedan circunscritos al ámbito de sus seguidores o fieles. Ello se extiende a las formas más suaves del carisma, aunque de modo más atenuado, como se colige de las consecuencias de la fama, el glamour, la popularidad mediática o deportiva, y demás.

Lo que aquí nos interesa es la relación que ciertas formas de carisma mantienen con la fraternidad y el altruismo. Consideremos tres aspectos de ella.

A Weber le intrigaban las exigencias característicamente imposibles de ciertos imperativos religiosos como "ama a tu prójimo como a ti mismo", o "pon la otra mejilla". Intentó explicarlas mediante la poderosa presencia de las cualidades carismáticas de un texto sagrado, o por las órdenes del guía, fuese éste profeta, caudillo o jefe político. Los mandamientos nacidos de ellos, prácticamente imposibles de seguir, escapan todas las normas de la paradoja de Arrow, empezando por el hecho de que los gobernantes, en democracia, han de serlo secular y deliberativamente (por lo menos, mínimamente). A pesar de su intrínseca dificultad de cumplimiento dichos mandamientos generan en sus seguidores niveles apreciables de conducta altruista. Obviamente, rara vez estimulan un altruismo generalizado. Pero cierto altruismo selectivo, o benevolencia ocasional hacia "los otros" suele acaecer también. Se halla presuntamente inspirado en imperativos carismáticos de esta índole.

La atribución de carisma a procesos, acontecimientos y fenómenos varios puede resultar a veces en acción solidaria o fraterna. La celebración de la naturaleza, por ejemplo, puede llegar a manifestarse en adoración de la tierra o del cosmos, o piedad cósmica (Giner y Tábara, 1999) con repercusiones beneficiosas para la sostenibilidad de la vida humana en la Tierra. El caso de los cultos ecologistas, más allá de las decisiones racionales tomadas por ciudadanos, empresas y gobiernos en favor de un ambiente decente, persuadidos de que la naturaleza necesita protección, es un ejemplo de los efectos solidarios y hasta fraternos de cierta atribución mística - franciscana- o carismática a la madre naturaleza ${ }^{5}$. Se hace patente que el carisma no puede definirse, sin más, como fenómeno irracional o tenebroso ${ }^{6}$. Podría estar ligado, o no, a la acción irracional. Amor patriae se presta, a veces, a degradarse en nacionalismo fanático, pero es, muy a menudo, un sentimiento perfectamente racional y razonable, capaz de gene-

\footnotetext{
5 Un caso de "racionalidad cognitiva", como en Boudon (2003: 62).

${ }^{6}$ Escrito esto —basado en Giner (2003: 53) - constato el aserto de R. Boudon: "La notion de charisme ne renvoie pas nécessairement à des forces obscures" (Boudon, 2003: 53).
} 
rar un comportamiento civilizado, respetuoso y legal, como Maquiavelo y tantos otros pensadores republicanos no se han cansado de repetir. La posibilidad de la racionalidad del carisma — de ciertas formas del mismo, se entiende- debe ser tomada en serio por la ciencia social.

Del mismo modo que he descartado vagos factores culturalistas como poco útiles para el análisis sociológico del comportamiento altruista, sugiero que el carisma, que es siempre concreto, encarnado en personas, textos sagrados o canónicos y objetos numinosos, es una herramienta más potente que la invocación culturalista para el estudio del altruismo. La recién mencionada piedad cósmica ilustra lo que sostengo, pero también la presencia de guías carismáticos recientes, como el Abbé Pierre en Francia y la Madre Teresa de Calcuta. U hoy, el padre Casaldàliga en el Brasil, por mencionar sólo tres de los más conocidos en el ámbito católico. Estos encarnan las virtudes necesarios para inspirar el comportamiento desprendido y la entrega hacia terceros propios de la conducta altruista a una escala sustancial ${ }^{7}$.

\section{V}

Desde una perspectiva arroviana, mucho es lo que cae fuera de lo calculable en el campo de las decisiones públicas sobre bienestar colectivo y también en el del altruismo. Los hechos confirman la validez de su teorema de imposibilidad en las condiciones de secularidad, racionalidad y democracia mínima en las que es válido. Sin embargo, muchas son las decisiones que, según otro criterio, deben ser consideradas como posibles, siempre y cuando intervenga carisma.

En efecto, el carisma establece, entre sus fieles, prioridades que excluyen cálculo. Por definición. Lo santo debe obedecerse. Las declaraciones del profeta, el caudillo político, el enviado de los dioses, exigen cumplimiento. La elección de conducta a seguir se hace entonces posible porque no sólo sabemos lo que es moralmente correcto sino también lo que debe hacerse primero. Se establece así un orden societario de prioridades $^{8}$. La paradoja de Arrow —en este campo específico— queda así superada. No se aplica cuando una autoridad carismática es débil y está muy diluida ni tampoco cuando el poder que ejerce se halla excesivamente rutinizado o secularizado. Sí en cambio cuando su carisma es intenso.

Enunciaré un teorema de posibilidad de la conducta altruista, del modo siguiente: la invocación de creencias carismáticamente mantenidas puede facilitar un curso de acción genuinamente altruista, bajo determinadas condiciones. En tal caso, bajo el imperativo carismático, se toman decisiones solidarias a favor de prójimos desvalidos o necesita-

\footnotetext{
${ }^{7}$ Su estudio estimularía la consideración sociológica del "ejemplo moral" en la consolidación de los ideales éticos de los humanos, dadas las fuertes inclinaciones antropocéntricas de la imaginación de la mayoría.

${ }^{8}$ Para el origen religioso de las decisiones políticas cf. Bubner (2006)
} 
dos que no hubieran tenido lugar si solamente el análisis calculador y consecuencialista —utilitarista- las hubiera justificado.

Por consiguiente, en tal caso, aquello que el procedimiento de la tría racional —una "función de bienestar" enteramente imparcial- a menudo imposibilita es, en cambio, posibilitado por el imperativo de la adscripción carismática.

El carisma posee siempre un componente descriptivo, pero es, crucialmente, un fenómeno prescriptivo. Además, entraña acción no deliberativa, hasta ciega. Lo sagrado no se negocia. Con un guía, jefe o caudillo ungido por la historia o la providencia tampoco se negocia. En el reino de las creencias imperativas la lógica interna no es esencial.

En él, las prioridades no se establecen según las normas de la lógica secular y racional. La última florece en el mundo de la Gesellschaft. En la Gemeinschaft, en cambio, lo que es deseable y posible no siempre puede reducirse a un análisis de coste/beneficios, a un cálculo felicífico, o a un orden de prioridades basado en un rango de principios a aplicar. Las creencias carismáticas rehúyen las divisiones y las separaciones, exigen unión, comunión y unicidad. Las más interesantes de tales creencias —tal vez las únicas realmente interesantes - piden la inclusión de todos y no sólo la de los iniciados y los fieles. Exigen fraternidad.

Sin embargo, el carisma es esencialmente ambivalente. Puede exigir trato fraterno con el infiel, el descreído, el forastero, hasta con el enemigo. Pero puede también pedir su destrucción, su demonización. El terrorismo político y las ideologías fanáticas se hallan asimismo ligadas invariablemente a las creencias carismáticas. Ignorar esta ambivalencia haría inútil cualquier teoría de la solidaridad y la fraternidad fundamentada en ese fenómeno social crucial que es el carisma. Esta ambivalencia no es una mera dualidad: siempre hay tensión entre la dimensión agresiva de la afirmación del carisma -incluidos los beneficios que otorga a "los suyos": el pueblo elegido, la comunidad de los creyentes, los miembros del partido- y sus repercusiones sobre las gentes que quedan fuera de su círculo "bendito" o "afortunado". Como ya sabemos por incontables guerras religiosas y persecuciones políticas, el carisma engendra bienaventuranza y confianza entre sus adoradores o fieles pero desolación y desdicha entre aquellos extraños que son sus víctimas. Es inherentemente peligroso (Douglas, 1979).

Si ello se tiene en cuenta nos encontraremos en mejor posición para analizar qué creencias y ligámenes carismáticos inclinan a los humanos a actuar de modo solidario y fraterno, libres de cálculos utilitaristas y estrictamente egoístas.

\section{VI}

Todas las ideologías definen el altruismo como imperativo moral. Ninguna de ellas se presenta como programa para el fomento del mal. Todas se adornan de un componente "salvacionista", incluso las que proclaman la supremacía de una raza o partido. (La clase dominante, o la raza conquistadora, manda en nombre de la humanidad, pero sobre todo para sus subordinados "naturales", que están mejor si la obedecen. Hasta las proclamas 
de la Herrenrasse nazi asumían tales pretensiones.) Eso sí, el imperativo altruista puede ser una prioridad no de primer, sino de segundo orden, dentro de la dimensión moral de una ideología dada. La tríada conceptual "Libertad, Igualdad, Fraternidad" o el mensaje cristiano tal y como aparece en el Evangelio de San Mateo enaltecen el altruismo, ya en nombre de la hermandad del hombre ya en guisa de caridad. No necesitamos aceptar un reduccionismo paretiano de cualquier declaración de buena voluntad o solidaridad como un mero flatus vocis o, para usar su vocabulario, como mera "derivación" de potentes instintos escondidos, para aceptar que intenciones manifestadas por esas expresiones de compasión, buena voluntad o solicitud no son ni necesaria ni cínicamente falsas. Otra cosa es reconocer que la vida social se rige predominantemente por ellas, sobre todo en situaciones en las que están presentes la concurrencia económica y las fuerzas del mercado, por no hablar de la guerra, la lucha política, la penuria y la pobreza.

También es cierto que las semillas de un retorno eficaz y permanente hacía la primacía del principio de solidaridad han sido sembradas por ideologías como las mentadas. La sociología de la religión, y Max Weber particularmente, ha dedicado gran atención a este fenómeno en el estudio de la formación de sectas y como estímulo para reformas, revisiones y rebeliones en el seno de las religiones establecidas. Los movimientos de renovación desean volver al "verdadero" espíritu de los orígenes de sus creencias, presuntamente traicionadas por los conservadores reinantes (Giner y López, 2008). Lo mismo puede decirse de ideologías políticas y movimientos sociales comparables. Diversos movimientos sociales orientados hacia la solidaridad (asociaciones cívicas altruistas, es decir, ONG) han surgido explícitamente contra aquello que entienden como un fracaso de los partidos y los gobiernos al no actuar generosa y altruistamente hacia las naciones pobres, o para mitigar con eficacia los problemas de los miserables, los enfermos y los hambrientos.

El estado asistencial mismo, con su vasta maquinaria en salud pública, educación para todos, pensiones y subsidios universales, es resultado de principios establecidos en la moderna transformación de la noción liberal originaria del ciudadano en otra en la que se entronizan los ideales de derechos compartidos y de responsabilidades comunes. A su vez, esta mudanza no está libre de contradicciones, pero eso es otro asunto 9 . Sería erróneo extender el poder carismático, que ejerce su influjo sobre el comportamiento de las gentes, al aparato público asistencial y de bienestar. La ciudadanía con frecuencia asume resignada y vagamente que está bien que una parte sustancial de sus ingresos sea captado por el fisco para financiar la salud, educación, el orden público y otros servicios, sin mayor justificación metafísica —o místico-carismática- de que tal es el orden legal establecido. Y no sólo porque la alternativa a rehusar la contribución sea delito punible. ${ }^{10}$

\footnotetext{
${ }^{9}$ He explorado tales contradicciones en Giner (2007).

${ }^{10}$ Debo esta observación a Luis Moreno.
} 
Aunque sus efectos sean profundos y sus repercusiones vastas, el carisma manda con frecuencia sobre un ámbito circunscrito. La debilitación del carisma puede ser fortísima y quedar muy diluida y dispersa, como es el caso de aquello que otrora inspiró el estado asistencial y es ahora su burocracia y servicios redistributivos. Puede ser mayor que su ritualización. Ambos procesos están estrechamente relacionados entre sí, pero son esencialmente distintos.

Bajo los imperativos del carisma, solidaridad, caridad, compasión y fraternidad, vinculadas a lo sagrado - sea éste sobrenatural o mundano- se soslayan en algunos casos las exigencias del egoísmo normal. La ciencia social, pero también la filosofía moral, ha descuidado este campo de exploración. La fraternidad sigue siendo un enigma a desvelar. El teorema de posibilidad abre una rendija para vislumbrarlo.

\section{REFERENCIAS BibLIOgRÁFICAS}

Arrow, J. K. 1951. Social Choice and Individual Values. New Haven: Yale: University Press.

Berlin, I. 1996. "On Political Judgement". The New York Review of Books 3: 26-30.

Boudon, R. 2003. Raisons, bonnes raisons. París: PUF.

Douglas, M. 1970. Purity and Danger. Londres: Routledge and Kegan Paul.

Giner, S. 1997. "Intenciones humanas, estructuras sociales: para una lógica situacional". En M. Cruz (comp.) Acción Humana, pp. 121-126. Barcelona: Ariel.

Giner, S. 2003. Carisma y razón. Madrid: Alianza.

Giner, S. 2007. "Dignidad Cívica”. Claves 173: 4-15.

Giner, S. y J.D. Tàbara. 1999. "Cosmic Piety and Ecological Rationality”. International Sociology 14: 59-82.

Shils, E. 1975. "The Sanctity of Life". Center and Periphery. Chicago: The University of Chicago Press.

SALVADOR GINER DE SAN JULIÁN es Profesor emérito de sociología (MA, Ph.D. Universidad de Chicago). Presidente del Institut d"Estudis Catalans, academia de las ciencias y humanidades, en Barcelona. Fue director de la Revista Internacional de Sociología. Autor de Carisma y Razón y coeditor del Diccionario de Sociología (ambos en Alianza Editorial) así como de Historia del pensamiento social y de Teoría sociológica clásica (ambos en Ariel).

RECIBIDO: $13 / 01 / 2008$

ACEPTADO: 26/11/2008

Publicado on-line: 19 de Noviembre de 2009 